\title{
Cyanobacterial growth and cyanophycin production with urea and ammonium as nitrogen source
}

\author{
S. Canizales ${ }^{1,2} \cdot$ M. Sliwszcinka ${ }^{1} \cdot$ A. Russo ${ }^{1,3} \cdot$ S. Bentvelzen ${ }^{1} \cdot$ H. Temmink ${ }^{1,3} \cdot$ A. M. Verschoor ${ }^{1,4} \cdot$ R. H. Wijffels ${ }^{2,5}$. \\ M. Janssen ${ }^{2}$
}

Received: 5 April 2021 / Revised: 16 June 2021 / Accepted: 16 July 2021 / Published online: 16 August 2021

(c) The Author(s) 2021

\begin{abstract}
Several technologies have aimed to recover nitrogen directly from urine. Nitrogen recovery in these technologies was limited by the mismatch of the nitrogen-phosphorus molar ratio (N:P) of urine, being 30-46:1, and that of the final product, e.g., 1:1 in struvite and 16-22:1 in microalgae biomass. Additionally, the high nitrogen concentrations found in urine can be inhibitive for growth of microorganisms. Cyanobacteria were expected to overcome phosphorus (P) limitation in urine given their ability to store an N-rich polymer called cyanophycin. In this study, it was found that the model cyanobacterium Synechocystis sp. PCC6803 did not experience significant growth inhibition when cultivated in synthetic medium with concentrations of $0.5 \mathrm{~g}$ ammonium-N L ${ }^{-1}$. In the case of urea, no inhibition was observed when having it as sole nitrogen source, but it resulted in chlorosis of the cultures when the process reached stationary phase. Synechocystis was successfully cultivated in a medium with $0.5 \mathrm{~g}$ ammonium-N L ${ }^{-1}$ and a $\mathrm{N}: \mathrm{P}$ ratio of 276:1, showing the N:P flexibility of this biomass, reaching biomass $\mathrm{N}: \mathrm{P}$ ratios up to $92: 1$. Phosphorus starvation resulted in cyanophycin accumulation up to $4 \%$. Dilution of the culture in fresh medium with the addition of $118 \mathrm{mg} \mathrm{N} \mathrm{L}^{-1}$ and $1.5 \mathrm{mg} \mathrm{P} \mathrm{L}^{-1}(\mathrm{~N}: \mathrm{P}$ of 174:1) resulted in a rapid and transient cyanophycin accumulation up to $11 \%$, after which cyanophycin levels rapidly decreased to $3 \%$.
\end{abstract}

Keywords Cyanobacteria $\cdot$ Synechocystis $\cdot$ Cyanophycin $\cdot$ Nutrients recovery $\cdot$ Urea $\cdot$ Ammonium $\cdot$ Urine

\section{Introduction}

The development of the Haber-Bosch process (artificial fixation of nitrogen) has resulted in a $35-55 \%$ addition of reactive nitrogen to the natural nitrogen fixation rates. This process requires a lot of energy $\left(37 \mathrm{~kJ} \mathrm{~g}_{\mathrm{N}}{ }^{-1}\right)$ and a hydrogen source, generally natural gas, and therefore cannot be considered very sustainable (Maurer et al. 2003; Howarth

S. Canizales

sebastian.canizalesgomez@wur.nl

1 Wetsus, Centre of Excellence for Sustainable Water Technology, Oostergoweg 9, Leeuwarden, The Netherlands

2 Bioprocess Engineering, AlgaePARC, Wageningen University, Wageningen, The Netherlands

3 Department of Environmental Technology, Wageningen University, Wageningen, The Netherlands

4 Wageningen Food Safety Research, Wageningen, The Netherlands

5 Faculty of Biosciences and Aquaculture, Nord University, N-8049 Bod $\varnothing$, Norway
2008). Most of the fixed nitrogen is used in the agro-industrial food production and as a consequence, today, approximately $80 \%$ of the nitrogen in human tissues stems from the Haber-Bosch process (Howarth 2008). The nitrogen consumed in food is later excreted from the human body as an important constituent of urine and often ends up in the domestic wastewater. More than $80 \%$ of wastewater produced worldwide is released to the environment without proper treatment (Connor et al. 2017). The release of the nitrogen in (treated) wastewater causes severe environmental impacts including eutrophication (Rockström et al. 2009) and climate change (Kampschreur et al. 2009). Nitrogen is removed from wastewater by subsequent nitrification and denitrification and is released back to the atmosphere as dinitrogen gas. Also, this process requires a lot of energy ( $45 \mathrm{~kJ} \mathrm{~g}_{\mathrm{N}}{ }^{-1}$ ) for aeration during nitrification and consumption of valuable carbon sources for denitrification (Maurer et al. 2003; Morales et al. 2013). Therefore, sustainable technologies to reduce the environmental impact related to nitrogen should focus on its recovery and reuse. 
Human urine contributes $70 \%$ of the nitrogen load present in municipal wastewater while the contribution to the total wastewater volume is $1 \%$ (Kujawa-Roeleveld and Zeeman 2006). Urine also contributes up to $40 \%$ of the phosphorus (P) and $60 \%$ of the potassium $(\mathrm{K})$ load present in municipal wastewater (Kujawa-Roeleveld and Zeeman 2006). This high content of nutrients explains why several technologies have been studied aiming to simultaneously recover nitrogen and phosphorus from urine. However, the high $\mathrm{N}: \mathrm{P}$ molar ratio of urine (30-46:1) presents a bottleneck for such technologies. For example, struvite precipitation and microalgae biomass cultivation result in products with N:P ratios of 1:1 (Maurer et al. 2003) and 16-22:1 (Redfield 1958; Tuantet et al. 2014b; Vasconcelos Fernandes et al. 2015), respectively, i.e., significantly lower than the N:P ratio of urine. This implies only phosphorus can be fully recovered while removal of the remaining nitrogen requires post-treatment.

Nitrogen is present in urine mainly in form of urea and ammonium (both $\mathrm{NH}_{3}$ and $\mathrm{NH}_{4}^{+}$unless stated otherwise), depending on the storage time. In fresh urine, most of the nitrogen is present in form of urea but this is hydrolyzed into ammonium and bicarbonate in a matter of days through a process called ureolysis (Liu et al. 2008). Ureolysis is catalyzed by the enzyme urease, which is present in the cytoplasm of a large variety of microorganisms. Since ammonia $\left(\mathrm{NH}_{3}\right)$ is toxic for microorganisms, the ammonium concentration and $\mathrm{pH}$ are critical parameters for the cultivation of microalgae and other microorganisms on urine (Drath et al. 2008; Dai et al. 2014). The high concentration of nitrogen in human urine of 2.3 to $7.2 \mathrm{~g} \mathrm{~N} \mathrm{~L}^{-1}$ (Tuantet et al. 2014a, b), present mostly in form of ammonium, can inhibit microalgae growth due to ammonia toxicity. For example, Arthrospira platensis was inhibited by concentrations of $50 \mathrm{mg} \mathrm{N} \mathrm{L}^{-1}$ (Feng and Wu 2006) and Scenedesmus acuminatus was inhibited even at concentrations of $10 \mathrm{mg} \mathrm{N} \mathrm{L}^{-1}$ (Adamsson 2000). A more robust strain was $C$. sorokiniana that had growth inhibition at concentrations higher than $1.4 \mathrm{~g} \mathrm{~N} \mathrm{~L}^{-1}$ (Zhang et al. 2014).

Cyanobacteria carry out oxygenic photosynthesis and are often referred to as microalgae although they are prokaryotic. When facing stress conditions, they can accumulate compounds such as polyphosphates for phosphorus storage, cyanophycin $(\mathrm{CP})$ or phycobiliproteins for nitrogen storage (Allen et al. 1984; Kromkamp 1987), and glycogen or polyhydroxybutyrate as carbon storage. Cyanophycin (multi-Larginyl-poly-L-aspartate) is a non-ribosomal nitrogen-rich copolymer consisting of equimolar amounts of aspartic acid and arginine (Simon and Weathers 1976; Krehenbrink et al. 2002; Obst and Steinbu 2004; Maheswaran et al. 2006). At neutral $\mathrm{pH}$ and physiological ionic strength, cyanophycin is insoluble and accumulates in the cytoplasm as membraneless granules (Allen and Weathers 1980; Sukenik et al. 2015). Cyanophycin in particular may be interesting because it can be chemically converted into polyaspartic acid (Joentgen et al. 2001), and in this form, it is a renewable alternative for synthetic polyacrylate (Neumann et al. 2005). Cyanophycin can also be applied as a dispersant, or for reducing corrosion in petroleum and natural gas production (Mooibroek et al. 2007).

Synthesis of cyanophycin requires ATP, $\mathrm{K}^{+}, \mathrm{Mg}^{2+}$, a sulfhydryl reagent, and a CP-primer as starting frame for the incorporation of the amino acids (Simon 1973; Kromkamp 1987). Under phosphorus starvation, the wild type of Synechocystis sp. PCC6803 can accumulate up to $18 \%$ of cyanophycin on a dry weight basis (Trautmann et al. 2016). An engineered Synechocystis PCC6803 (BW86) could even accumulate up to $47 \%$ cyanophycin under phosphorus starvation and $57 \%$ under potassium starvation (Watzer et al. 2015). The cyanobacteria can use cyanophycin as a temporary nitrogen reserve to be used as soon as growth is resumed (Allen et al. 1984; Mackerras et al. 1990). Apart from phosphorus starvation, cyanophycin can also be accumulated by cyanobacteria in the absence of light or under sulfate limiting conditions (Watzer and Forchhammer 2018a). Therefore, Synechocystis sp. PCC6803 (Synechocystis 6803 from now on) could be an interesting strain to remove or recover nutrients from urine because under phosphorus-limiting conditions, Synechocystis 6803 can still take up nitrogen and accumulate it as cyanophycin (Trautmann et al. 2016). The molar $\mathrm{N}: \mathrm{P}$ ratio of Synechocystis 6803 may be more favorable for simultaneous nitrogen and phosphorous removal from urine than of other phototrophic microorganisms.

Synechocystis 6803 is a widely studied cyanobacterial strain that is relatively easy to cultivate in suspension and which is able to use ammonium, urea, and nitrate as nitrogen sources (Valladares et al. 2002; Kolodny et al. 2006). Trautmann et al. reported that Synechocystis 6803 accumulated cyanophycin as soon as the biomass phosphorus quota $\left(q_{\mathrm{P}}\right)$ were lower than 1-4 $\mathrm{mg} \mathrm{P} \mathrm{g} \mathrm{DW}^{-1}$ (Trautmann et al. 2016). However, most of these experiments were carried out under axenic conditions with nitrate as the nitrogen source (Hai et al. 2000; Watzer et al. 2015), which cannot be extrapolated to treatment of urine containing urea and/or $\mathrm{NH}_{4}{ }^{+}$. The few results available with $\mathrm{NH}_{4}{ }^{+}$as the nitrogen source for Synechocystis 6803 gave a much lower cyanophycin content of 3\% (Watzer et al. 2015) and a transient accumulation of $7 \%$ in another strain of the same genus Synechocystis sp. PCC6308 in nitrogen-starved cells after addition of ammonium (Mackerras et al. 1990).

Ammonium $\left(\mathrm{NH}_{4}{ }^{+}\right)$is the preferred nitrogen source in cyanobacteria, since it can be directly incorporated into the carbon-skeletons of organic molecules through the glutamine synthetase-glutamate synthase pathway (GSGOGAT) (Valladares et al. 2002; Flores and Herrero 2005). Ammonium uptake is controlled by permeases of the Amt family (Montesinos et al. 1998); ammonium transport occurs 
through a symporter (Ortiz-ramirez et al. 2011) and transport rates are concentration gradient dependent (Fong et al. 2007). However, the toxic form ammonia $\left(\mathrm{NH}_{3}\right)$ can also be present in the medium depending on the $\mathrm{pH}$. At $\mathrm{pH}$ values above 9.25 (pKa of ammonium), $\mathrm{NH}_{3}$ is the most abundant species in the equilibrium $\mathrm{NH}_{4}{ }^{+} / \mathrm{NH}_{3}$ and this freely diffuses through the cell membranes (Kleiner 1981; Drath et al. 2008). Since $\mathrm{NH}_{3}$ binds to the oxygen evolution centers as a competitive analogue to water, this results in an increased photosensitivity and photodamage of photosystem II (PSII) (Evans et al. 2005). At non-inhibiting concentrations, cyanobacterial cells repair this photodamage by the action of a PSII repair system (Drath et al. 2008). This suggests a tradeoff between the rate at which PSII experiences photodamage and the rate at which it is repaired (Dai et al. 2014). At high concentrations of $\mathrm{NH}_{3}$, the rate at which photodamage occurs is higher than the rate at which PSII is repaired. This results in a decreased growth rate that we call $\mathrm{NH}_{3}$ inhibition. The photodamage that results in $\mathrm{NH}_{3}$ growth inhibition is by definition enhanced by higher light intensities (Dai et al. 2014).

Also, urea can freely diffuse through the phospholipidic bilayer of cyanobacteria (Siewe et al. 1998; Goodman 2002; Sachs et al. 2006). The urea is subsequently metabolized with an intracellular urease that hydrolyzes urea into $\mathrm{NH}_{4}{ }^{+}$ and bicarbonate $\left(\mathrm{HCO}_{3}^{-}\right)$(Al-Thawadi 2011). The activity and expression of this enzyme seem to be independent of the concentration of urea in the medium (Mackerras and Smith 1986) and in Synechocystis the ureolytic reaction seems to occur in an uncontrolled manner (Herrero et al. 2001). In the strains Anabaena sp. PCC7120, Synechocystis sp. PCC6803, and Synechococcus sp. PCC7002, bleaching of cultures was observed when cultivated under a light intensity of $250 \mu \mathrm{mol}$ photons $\mathrm{m}^{-2} \mathrm{~s}^{-1}$ on urea as nitrogen source at concentrations of $0.14,0.70$, and $1.40 \mathrm{~g}$ urea-N $\mathrm{L}^{-1}$ respectively just after the cultures reached stationary phase (Sakamoto et al. 1998). This bleaching, which is also called chlorosis, is the process of degradation of the light-harvesting pigments of photosynthetic cells. The induction of chlorosis can have different origin and involve different cellular mechanisms such as nitrogen limitation that results in not only reversible chlorosis (Forchhammer and Schwarz 2019) and light stress (Nixon et al. 2005), but also ammonia toxicity (Drath et al. 2008). Urea-related chlorosis occurred only in ureasepositive cyanobacteria and did not occur in urease deletion mutants of Synechococcus sp. PCC7002 nor in the ureasenegative strain Synechococcus sp. PCC6103 (Sakamoto et al. 1998). Urea-related chlorosis is irreversible and seems to be an intracellular process associated to an increase of internal $\mathrm{pH}$ and $\mathrm{NH}_{3}$ concentration due to ureolysis (Sakamoto et al. 1998). Perhaps at higher urea concentrations, such as those in fresh urine, cyanobacteria undergo chlorosis due to an increased intracellular $\mathrm{NH}_{3}$ accumulation, as a result of an imbalance between fast ureolytic activity and a slow rate of nitrogen incorporation (i.e., growth).

In this study, we explored the possibility of growing cyanobacteria on nitrogen-rich, phosphorus-poor media simulating diluted human urine. In addition, we studied the production of cyanophycin under these conditions. Synechocystis 6803 was cultivated in sequence batch experiments at increasing concentrations of either ammonium or urea to determine the toxicity thresholds for these $\mathrm{N}$-sources. After identifying safe nitrogen concentrations, Synechocystis 6803 was cultivated in batch mode in short light path photobioreactors (PBRs) on a medium with an ammonium nitrogen concentration of $0.5 \mathrm{~g} \mathrm{~N}$ $\mathrm{L}^{-1}$ and a high $\mathrm{N}: \mathrm{P}$ molar ratio of 276:1.

This high N:P ratio was calculated to force cyanophycin accumulation and to determine if Synechocystis 6803 biomass is able to overcome phosphorus limitation and continue nitrogen uptake after phosphorus has been depleted. These experiments determine if Synechocystis 6803 can be used to simultaneously recover nitrogen and phosphorus from urine.

\section{Materials and methods}

\section{Media}

Experiments to study ammonium and urea inhibition were carried out with modified BG11 medium (Stanier et al. 1971) (Table 1).

The medium for the experiments on phosphorus starvation was formulated based on the traditional BG11 medium, supplemented to support a cyanobacterial biomass concentration above $5 \mathrm{~g} \mathrm{DW} \mathrm{L}^{-1}$. The supplemented formulation was based on the elemental composition of A. platensis reported by (Cornet et al. 1992; Cogne et al. 2003) resulting in a higher concentration of potassium (Table 1). Sulfate, iron, and EDTA were also added in higher amounts to avoid the limitations reported by van Alphen et al. (2018). The concentration of EDTA was increased to $37 \mathrm{mg} \mathrm{L}^{-1}$ for an improved chelation of trace elements (Table 1). No negative effects of increased concentrations of EDTA on growth of Synechocystis 6803 were reported by van Alphen et al., (2018) for concentrations up to $70 \mathrm{mg} \mathrm{L}^{-1}$. In this manner, it can be ensured that phosphorus is the only limiting factor triggering cyanophycin accumulation.

\section{Inoculum}

The strain of Synechocystis sp. PCC6803 was obtained from the Pasteur Culture Collection of Cyanobacteria (PCC) (Paris, France). Axenic pre-cultures for inoculation of the inhibition experiments were derived from the PCC inoculum and cultivated on modified BG11 using ammonium as nitrogen source (Table 1) under a light intensity of $100 \mu \mathrm{mol}$ 
Table 1 Elemental composition of media in $\mathrm{mg} \mathrm{L}^{-1}$

\begin{tabular}{|c|c|c|}
\hline Element/compound & $\begin{array}{l}\text { Nitrogen inhibition } \\
\text { medium (BG11) }\left(\mathrm{mg} \mathrm{L}^{-\mathbf{1}}\right)\end{array}$ & $\begin{array}{l}\text { P starvation } \\
\text { medium }\left(\mathrm{mg} \mathrm{L}^{-1}\right)\end{array}$ \\
\hline $\mathrm{N}$ & $247.19^{\mathrm{a}}$ & 500 \\
\hline $\mathrm{P}$ & 7.11 & $4^{b}$ \\
\hline $\mathrm{K}$ & 8.98 & 95 \\
\hline $\mathrm{S}$ & 9.79 & 33.38 \\
\hline $\mathrm{SO}_{4}$ & 29.34 & 100 \\
\hline $\mathrm{Ca}$ & 9.81 & 9.81 \\
\hline $\mathrm{Fe}$ & 0.64 & $2.48^{\mathrm{c}}$ \\
\hline $\mathrm{Zn}$ & 0.05 & 0.05 \\
\hline $\mathrm{Mg}$ & 9.89 & 9.89 \\
\hline $\mathrm{Mn}$ & 0.50 & 0.50 \\
\hline $\mathrm{B}$ & 0.50 & 0.50 \\
\hline $\mathrm{Cu}$ & 0.02 & 0.02 \\
\hline $\mathrm{Co}$ & 0.00001 & $0.00001^{\mathrm{d}}$ \\
\hline EDTA $\mathrm{Na}_{2} \mathrm{Mg}$ & 1.00 & 36.81 \\
\hline $\mathrm{N}: \mathrm{P}$ & $77: 1$ & $276: 1$ \\
\hline Buffer HEPES ${ }^{\mathrm{e}} / \mathrm{MOPS}^{\mathrm{f}}$ & $15 \mathrm{mM}$ & $15 \mathrm{mM}$ \\
\hline
\end{tabular}

${ }^{a}$ Value adjusted depending on requirements for experiments ammonia and urea inhibition as explained in respective section. ${ }^{\text {b}}$ Value adjusted to force $\mathrm{P}$ starvation. ${ }^{\mathrm{c}}$ Added as $\mathrm{FeCl}_{3}$ instead of ferric ammonium citrate. ${ }^{\mathrm{d}}$ Added as $\mathrm{CoCl}_{2}$ instead of $\mathrm{Co}\left(\mathrm{NO}_{3}\right)_{2}$. $\mathrm{pH}$ buffer used in precultures for inoculation of the ${ }^{\mathrm{e}}$ inhibition experiments and ${ }^{\mathrm{f}}$ of the phosphorus starvation experiments

photons $\mathrm{m}^{-2} \mathrm{~s}^{-1}$ of warm white LED. The pre-cultures were cultivated in 200- or 250-mL Erlenmeyer flasks in either 100 or $200 \mathrm{~mL}$ of medium respectively, which were placed on an orbital shaking plate at $120 \mathrm{rpm}$ at laboratory atmosphere and temperature (approx. $25^{\circ} \mathrm{C}$ ) and had an initial $\mathrm{OD}_{750}$ of 0.3 . The $\mathrm{pH}$ was controlled by addition of $15 \mathrm{mM}$ HEPES buffer, which buffers at pH 7.5 (Table 1). Axenic pre-cultures for inoculation of the experiments of phosphorus starvation were derived from the abovementioned pre-cultures and cultivated on $\mathrm{P}$ starvation medium with an initial $\mathrm{OD}_{750}$ of 0.3 (Table 1) under a light intensity of $200 \mu$ mol photons $\mathrm{m}^{-2} \mathrm{~s}^{-1}$ of cool white LED. These pre-cultures were cultivated in 250-mL Erlenmeyer flasks in $200 \mathrm{~mL}$ of medium in an Infors Multitron HT incubator (Infors, Switzerland) with orbital shaking at $120 \mathrm{rpm}$, in a $2.5 \% \mathrm{CO}_{2}$-enriched air atmosphere and controlled temperature of $35^{\circ} \mathrm{C}$. $\mathrm{pH}$ was controlled by addition of $15 \mathrm{mM}$ MOPS buffer $\mathrm{pH}$ 7.5.

\section{Urea and ammonium inhibition}

Synechocystis 6803 was cultivated at different concentrations of $\mathrm{NH}_{4}{ }^{+} \mathrm{N}$. The experiments were done in sequencing batch mode using the approach of Tuantet et al. (2014a) in four replicates. The experiments were carried out in Multicultivators MC-1000 OD (PSI Photon Systems Instruments, Czech
Republic) with automatic measurement of optical density (OD) at 680 and $720 \mathrm{~nm}\left(\mathrm{OD}_{680}\right.$ and $\left.\mathrm{OD}_{720}\right)$. The $\mathrm{pH}$ was controlled at 7.5, i.e., the optimum $\mathrm{pH}$ for Synechocystis 6803 (Zavrel et al. 2015), by addition of $1 \mathrm{~g} \mathrm{Na}_{2} \mathrm{CO}_{3} \mathrm{~L}^{-1}$ in the experiments with ammonium, and by addition of $15 \mathrm{mM}$ HEPES pH 7.5 in the experiments with urea. The Multicultivator tubes $(2.7 \mathrm{~cm}$ diameter) were filled with $85 \mathrm{~mL}$ of mineral medium BG11 modified for ammonium or urea as nitrogen source and maintained at a constant temperature of $35^{\circ} \mathrm{C}$.

The initial concentrations of nitrogen in the medium were $0.25,0.50,0.75,1.00,1.25$, and $1.50 \mathrm{~g} \mathrm{NH}_{4}^{+}-\mathrm{N} \mathrm{L}^{-1}$ for the experiments on ammonium and $0.11,0.22,0.34,0.45,0.56$, and $0.67 \mathrm{~g}$ Urea- $\mathrm{N} \mathrm{L}^{-1}$. The cultures were sparged with $5 \%$ $\mathrm{CO}_{2}$-enriched air at a flow of $100 \mathrm{~mL} \mathrm{~min}{ }^{-1}(0.85 \mathrm{vvm})$ and cultivated under light intensities of 100 or $200 \mu \mathrm{mol}$ photons $\mathrm{m}^{-2} \mathrm{~s}^{-1}$ of warm white LED light. $\mathrm{OD}_{720}$ was automatically measured every $10 \mathrm{~min}$ and for analysis, $1-\mathrm{h}$ averages were calculated using the last and next half hour. Growth rates of Synechocystis 6803 were determined by linear regression over each dilution cycle and expressed in $\mathrm{OD}_{720}$ day $^{-1}$. The linearity of the regression was verified by $R^{2}$ values above 0.95 .

\section{Cyanophycin accumulation on ammonium due to phosphorus starvation}

To determine the potential for cyanophycin accumulation by Synechocystis 6803, these were cultivated in batch mode in phosphorus starvation medium (Table 1). The cultivation was done in batch mode in 1.8-L flat-panel PBRs (Biostream International B.V, the Netherlands). Temperature and $\mathrm{pH}$ were controlled at $35^{\circ} \mathrm{C}$ and 7.5 respectively, and the PBR was mixed by sparging $1 \mathrm{~L} \mathrm{~min}^{-1}(0.56 \mathrm{vvm})$ of $2 \%$ $\mathrm{CO}_{2}$-enriched air to avoid carbon limitation. The $\mathrm{pH}$ was controlled by automatic addition of $1 \mathrm{M} \mathrm{NaOH}$. The formation of foam was controlled by automatic addition of a 1\% solution of Antifoam B Emulsion (Sigma-Aldrich). The PBRs logged light transmittance in the PAR region (400-700 nm). The light intensity in the PBR was set at $200 \mu \mathrm{mol}$ photons $\mathrm{m}^{-2} \mathrm{~s}^{-1}$. After growth of the culture had been observed (after $17 \mathrm{~h}$ ), the light intensity was increased to $600 \mu \mathrm{mol}$ photons $\mathrm{m}^{-2} \mathrm{~s}^{-1}$.

The medium was prepared under non-sterile conditions and was stored at $6{ }^{\circ} \mathrm{C}$ for maximally $24 \mathrm{~h}$. The day after medium preparation, the PBR was rinsed with Milli-Q ${ }^{\circledR}$ water and the gas supply started. Later, the medium was added to the PBR and left for $1 \mathrm{~h}$ while sparging the gas mix. This caused a $\mathrm{pH}$ drop in the medium. Therefore, the $\mathrm{pH}$ control was activated and the PBR was left for at least $2 \mathrm{~h}$ to allow the $1 \mathrm{M} \mathrm{NaOH}$ addition to achieve a $\mathrm{pH}$ of 7.5. A sample of the neutralized medium was taken for nutrient analyses. 
The cyanophycin accumulation experiments were done in two consecutive batch cultivation cycles. In batch 1 , we aimed to starve the culture on phosphorus aiming to trigger the accumulation of cyanophycin; therefore, a concentration of $4 \mathrm{mg} \mathrm{P} \mathrm{L}^{-1}$ was calculated for a $q_{\mathrm{P}}$ of $1-4 \mathrm{mg} \mathrm{P} \mathrm{g} \mathrm{DW}^{-1}$ at biomass concentrations above $1 \mathrm{~g} \mathrm{DW} \mathrm{L}^{-1}$. The PBR was inoculated under non-sterile conditions with $83 \mathrm{~mL}$ of axenic pre-culture aiming for an initial $\mathrm{OD}_{750}$ of 0.3 . Despite the low concentration of phosphorus in the medium, the biomass grew to the point at which light became co-limiting. Then, a second batch cycle (batch 1.1 and 1.2) was performed in two duplicate PBRs. This second batch cultivation was done with even lower availability of phosphorus aiming to force a stationary phase due to phosphorus limitation only. The dilution was done for both PBRs by adding $200 \mathrm{~mL}$ of culture from batch 1 into a mix of $600 \mathrm{~mL}$ of phosphorus starvation and 800-mL P-free medium (P-free medium does not contain any source of phosphorus). This resulted in an addition of $1.5 \mathrm{mg} \mathrm{P} \mathrm{L}^{-1}$ and $118 \mathrm{mg} \mathrm{N} \mathrm{L}^{-1}$ and sufficient other nutrients as specified in the medium formulation (Table 1).

\section{Sample processing and analyses}

In the experiments for the determination of ammonium and urea inhibition, $5-\mathrm{mL}$ samples were taken at the beginning and end of each cycle to manually determine optical density and $\mathrm{pH}$. In the experiments on phosphorus starvation, daily samples of less than $100 \mathrm{~mL}$ were taken to determine optical density at 750,720 , and $680 \mathrm{~nm}\left(\mathrm{OD}_{750}, \mathrm{OD}_{720}\right.$, and $\left.\mathrm{OD}_{680}\right)$, dry weight (DW), and cyanophycin content of biomass. The sample was divided into pre-weighted falcon tubes in duplicate of 15 to $20 \mathrm{~mL}$ for cyanophycin determination, $7-10 \mathrm{~mL}$ for DW determination, and the remaining volumes of at least $5 \mathrm{~mL}$ for OD. Optical density was measured in a bench spectrophotometer (UV-1280 UV-VIS Spectrophotometer, Shimadzu Corporation, Japan). The samples were diluted to values below 0.7 in order to stay in the linear range of the $\mathrm{OD}_{750}$ to DW correlation. The samples for cyanophycin and DW were centrifuged at $4000 \mathrm{rcf}$ and both supernatant and pellet were stored separately at $-20{ }^{\circ} \mathrm{C}$ for later analyses. The supernatants were used for nutrient analyses and the pellets for cyanophycin and DW determination, respectively. DW was determined by freeze drying after which the dry samples were digested to determine the phosphorus content of the biomass.

Cyanophycin extraction was done based on the method of Elbahloul et al. (2005) and quantified by the Sakaguchi reaction assay for arginine-containing proteins developed by Messineo (1966) with modifications of the procedure by Lippi et al. (2018).

All supernatant samples were pressure-filtered using $0.45-\mu \mathrm{m}$ filters (PTFE, VWR, The Netherlands) and tested for cation $\left(\mathrm{NH}_{4}^{+}, \mathrm{Ca}^{2+}, \mathrm{K}^{+}, \mathrm{Na}^{+}\right.$, and $\left.\mathrm{Mg}^{2+}\right)$ and anion $\left(\mathrm{Cl}^{-}\right.$, $\mathrm{NO}_{3}{ }^{-}, \mathrm{NO}_{2}{ }^{-}, \mathrm{SO}_{4}{ }^{2-}$ and $\mathrm{PO}_{4}{ }^{3-}$ ) concentration and elements. The concentration of anions and cations was assessed by an ion chromatograph IC Compact 761 (Metrohm, The Netherlands). The total and soluble elements of digested biomass and supernatant were determined by inductively coupled plasma-optical emission spectrometry (ICP-OES) by means of an ion Perkin-Elmer Optima 3000 DV spectrometer (USA). Biomass samples were submitted to $\mathrm{HNO}_{3}$ digestion using microwave-induced heating (MWD Milestone) at $148{ }^{\circ} \mathrm{C}$ during $45 \mathrm{~min}$ prior to ICP-OES analysis. All the chemicals used were of analytical grade.

\section{Results}

\section{Growth inhibition of Synechocystis 6803 by ammonium and urea}

Synechocystis 6803 had a typical growth course measured as the average increase of $\mathrm{OD}_{720}$ in four replicates of the sequence batch experiments at different nitrogen concentration. After inoculation, the cultures faced an acclimation period during the first two dilution cycles, resulting in changes of the biomass growth rate measured as $\mathrm{OD}_{720}$ day $^{-1}$. The cultures were diluted daily to keep them in the linear growth phase while avoiding photo-inhibition, until observing at least two consecutive stable growth rates. Growth rates with standard deviation of $5 \%$ or less were considered as stable; typically, those corresponding to the last two or three dilution cycles were averaged. In the example of Fig. 1 this was done for the last three data points of growth rate.

Synechocystis 6803 grew linearly between $\mathrm{OD}_{720}$ values of 0.3 and 0.6 on either ammonium $\left(\mathrm{NH}_{4}^{+}\right)$or urea; therefore, growth rates are presented in terms of $\mathrm{OD}_{720}$ day $^{-1}$ (Fig. 2). Urea inhibition was investigated at two different light intensities as will be discussed later. Ammonium inhibition was tested at a light intensity of $100 \mu \mathrm{mol}$ photons $\mathrm{m}^{-2} \mathrm{~s}^{-1}$. The highest growth rate on ammonium of 0.34 $\mathrm{OD}_{720}$ day ${ }^{-1}$ was observed at an $\mathrm{NH}_{4}{ }^{+}-\mathrm{N}$ concentration of $0.25 \mathrm{~g} \mathrm{~N} \mathrm{~L}^{-1}$. The growth rates decreased at higher $\mathrm{NH}_{4}{ }^{+}-\mathrm{N}$ concentrations (Fig. 2). Progressive growth inhibition was observed for values of $0.75 \mathrm{~g} \mathrm{NH}_{4}^{+}-\mathrm{N} \mathrm{L}^{-1}$ with an $18 \%$ decrease of the growth rate, $52 \%$ decrease at $1.25 \mathrm{~g} \mathrm{NH}_{4}{ }^{+} \mathrm{N}$ $\mathrm{L}^{-1}$, and even $100 \%$ (no growth) at $1.50 \mathrm{~g} \mathrm{NH}_{4}^{+}-\mathrm{N} \mathrm{L}^{-1}$. When cultivated on urea at light intensities of either 100 or $200 \mu \mathrm{mol}$ photons $\mathrm{m}^{-2} \mathrm{~s}^{-1}$, the average growth rates were $0.34 \pm 0.04$ and $0.61 \pm 0.04 \mathrm{OD}_{720}$ day $^{-1}$, respectively.

Chlorosis is a process of degradation of the light-harvesting pigments in photosynthetic organisms including cyanobacteria. Chlorosis occurred in several growth-limited cultures of Synechocystis 6803 cultivated in shaking flasks. These 
Fig. 1 Typical course of a sequence batch of Synechocystis 6803 growing on BG11 medium at a $\mathrm{pH}$ of 7.5 and with an ammonium nitrogen concentration of $0.25 \mathrm{~g} \mathrm{NH}_{4}^{+}-\mathrm{N} \mathrm{L}^{-1}$. The empty circles indicate the $1 \mathrm{~h}$ average values of $\mathrm{OD}_{720}$ taken every $10 \mathrm{~min}$, the empty squares represent biomass growth rates $\left(\mathrm{OD}_{720} \mathrm{day}^{-1}\right)$ of the linear growth range calculated by linear regression. The grey area indicates the $\mathrm{OD}_{720}$ range typically used for the linear regression to determine the growth rate. Growth rates are averages of 4 biological replicates; error bars represent the standard deviation

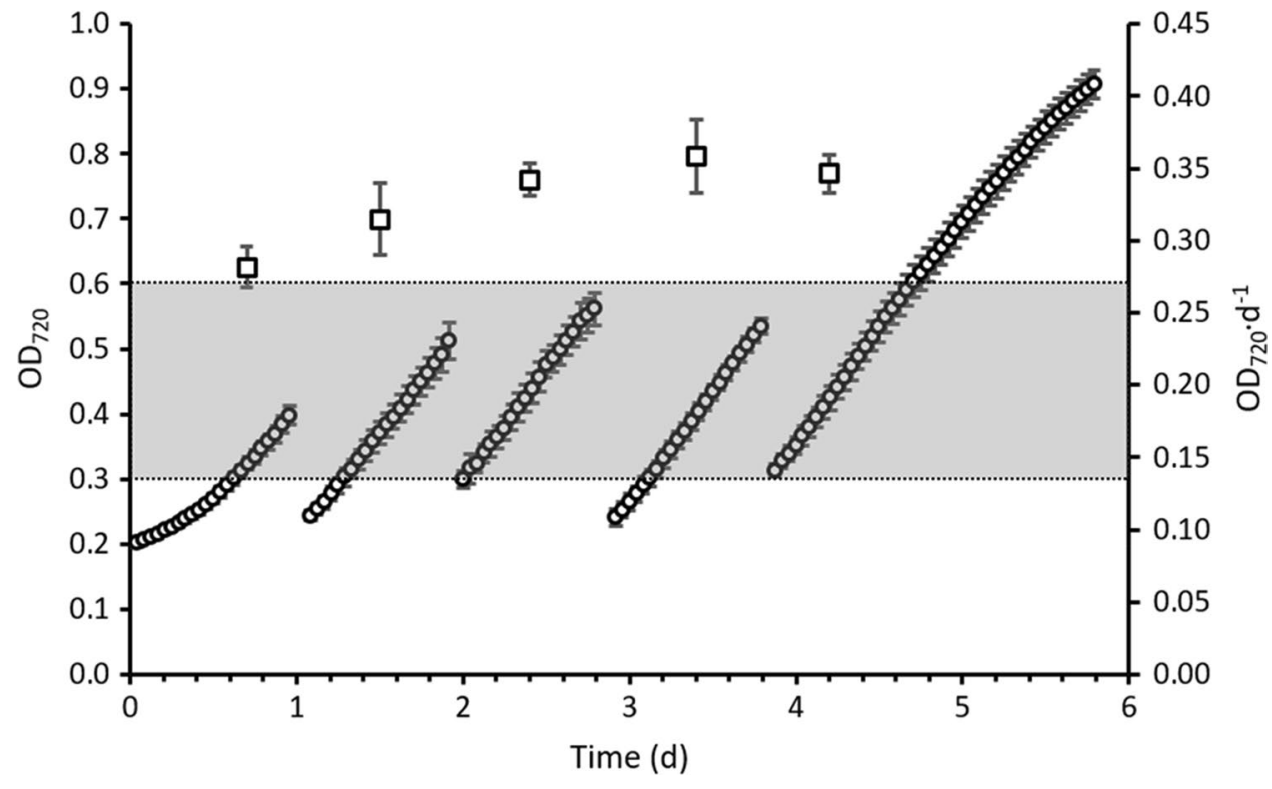

cultures were cultivated on concentrations of $0.5 \mathrm{~g}$ urea-N $\mathrm{L}^{-1}$ as sole nitrogen source, and the chlorosis occurred after they entered a stationary phase due to either light limitation or nutrient limitation (Fig. 3). This was not observed in the shaking flak cultures on ammonium; apparently, urea uptake was causing this chlorosis.

\section{Cyanophycin accumulation on ammonium due to phosphorus starvation}

To explore the feasibility of cyanophycin accumulation, Synechocystis 6803 was cultivated on a phosphorus-limited medium in flat-panel PBRs with an optical path of $2 \mathrm{~cm}$ and illuminated at $600 \mu \mathrm{mol}$ photons $\mathrm{m}^{-2} \mathrm{~s}^{-1}$. This experiment was designed to determine if nitrogen uptake would continue after phosphorus in the medium had been depleted, and to determine if part of the nitrogen would be accumulated as cyanophycin. In addition, the cultivation was performed under non-axenic conditions.

Despite the low availability of phosphorus of $3.0 \mathrm{mg} \mathrm{P} \mathrm{L}^{-1}$, just after inoculation of batch 1, the culture of Synechocystis 6803 exhibited a typical growth curve (Fig. 4A). The cyanophycin content of the inoculum was $10.7 \pm 1.3 \% \mathrm{CP}$ (Fig. 4B). This initial cyanophycin content was rapidly consumed, resulting in a content of only $0.2 \pm 0.2 \% \mathrm{CP}$ on day 1 (Fig. 4B). Cyanophycin accumulated again between days 1 and 3 reaching a
Fig. 2 Growth rate $\left(\mathrm{OD}_{720}\right.$ day $^{-1}$ ) during the linear growth phase of Synechocystis 6803 cultivated on modified BG11 with increasing concentrations of $\mathrm{NH}_{4}{ }^{+}-\mathrm{N}$ or Urea-N at a $\mathrm{pH}$ of 7.5 at a temperature of $35{ }^{\circ} \mathrm{C}$ and under a light intensity (LI) of 100 or $200 \mu \mathrm{mol}$ photons $\mathrm{m}^{-2} \mathrm{~s}^{-1}$. Averaged values determined by linear regression $\left(R^{2}=0.99\right)$. Error bars are the standard deviation of four replicates and are covered by the marker if not visible

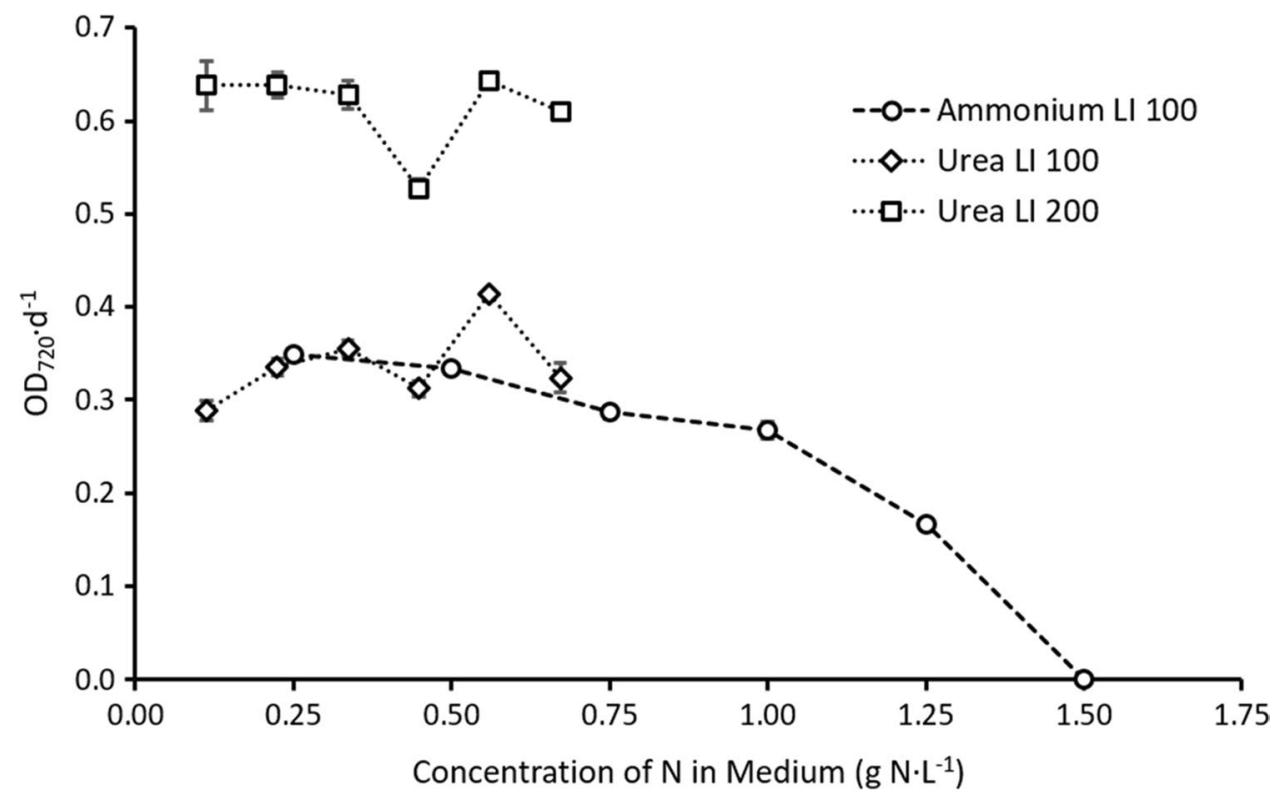


Fig. 3 Days 5 (top row), 6 (middle), and 7 (bottom) of stationary cultures of Synechocystis 6803 on urea (left) and ammonium (right) cultivated on $0.5 \mathrm{~g} \mathrm{~N}$ $\mathrm{L}^{-1}$ under a light intensity of $100 \mu \mathrm{mol}$ photons $\mathrm{m}^{-2} \mathrm{~s}^{-1}$

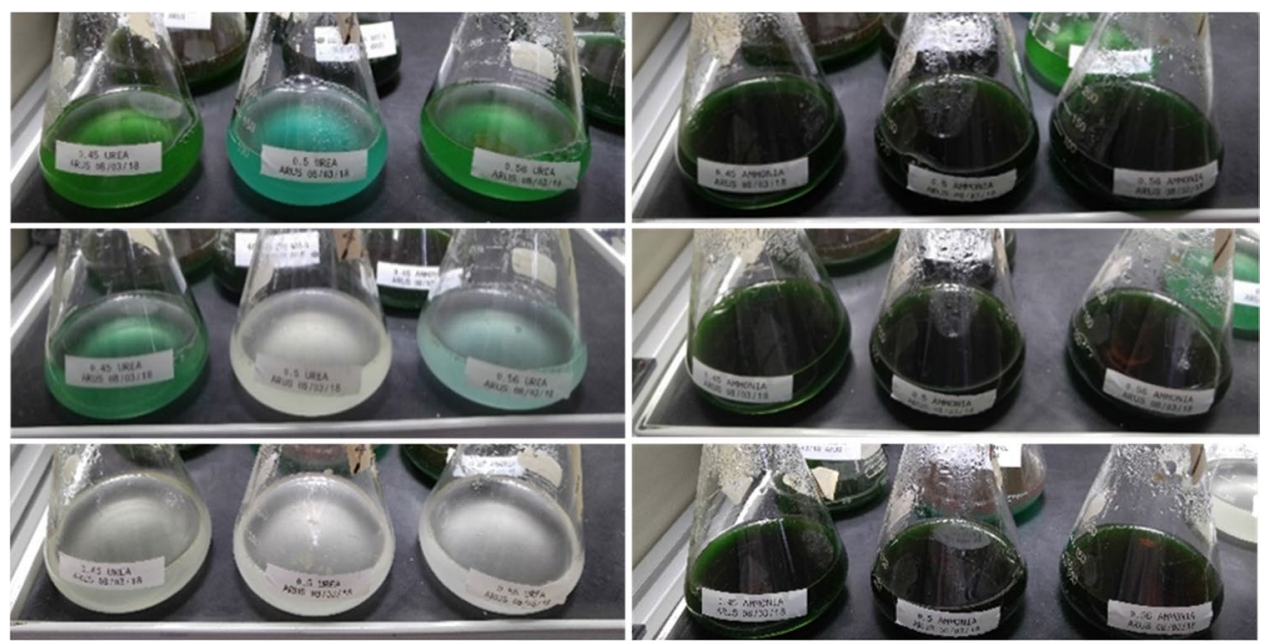

content of $4.3 \pm 0.1 \% \mathrm{CP}$ on day 2 (Fig. 4B). Subsequently, during stationary phase, the cyanophycin content slowly decreased to a value of $2.7 \pm 0.1 \% \mathrm{CP}$ and remained stable between days 7 and 14 .

Biomass growth in batch 1 depleted the phosphorus in the medium on day 2 (Fig. 5) and continued growing to a biomass concentration of $2.5 \mathrm{~g} \mathrm{DW} \mathrm{L}^{-1}$ (Fig. 4A), causing light co-limitation. This was confirmed by a calculated light absorption of $99 \%$ on day 3 corresponding to a light transmittance of $3 \mu \mathrm{mol}$ photons $\mathrm{m}^{-2} \mathrm{~s}^{-1}$. In a next step we diluted the PBRs aiming for phosphorus starvation at lower biomass concentration while allowing higher light availability. For
Fig. 4 A Biomass concentration of Synechocystis 6803 biomass cultivated on ammonium as nitrogen source under phosphorus-limiting conditions at a $\mathrm{pH}$ of 7.5 , a temperature of $35^{\circ} \mathrm{C}$, and under a light intensity of $600 \mu \mathrm{mol}$ photons $\mathrm{m}^{-2} \mathrm{~s}^{-1}$. B Cyanophycin content of the biomass as DW basis. Arrow on day 14 indicates the time at which batch 1 was diluted into batch 1.1 and 1.2. The dilution was done in such a way that $1.5 \mathrm{mg} \mathrm{P} \mathrm{L}^{-1}$ was available in the final mix. Error bars are the standard deviation of samples taken in duplicate and are covered by the marker if not visible

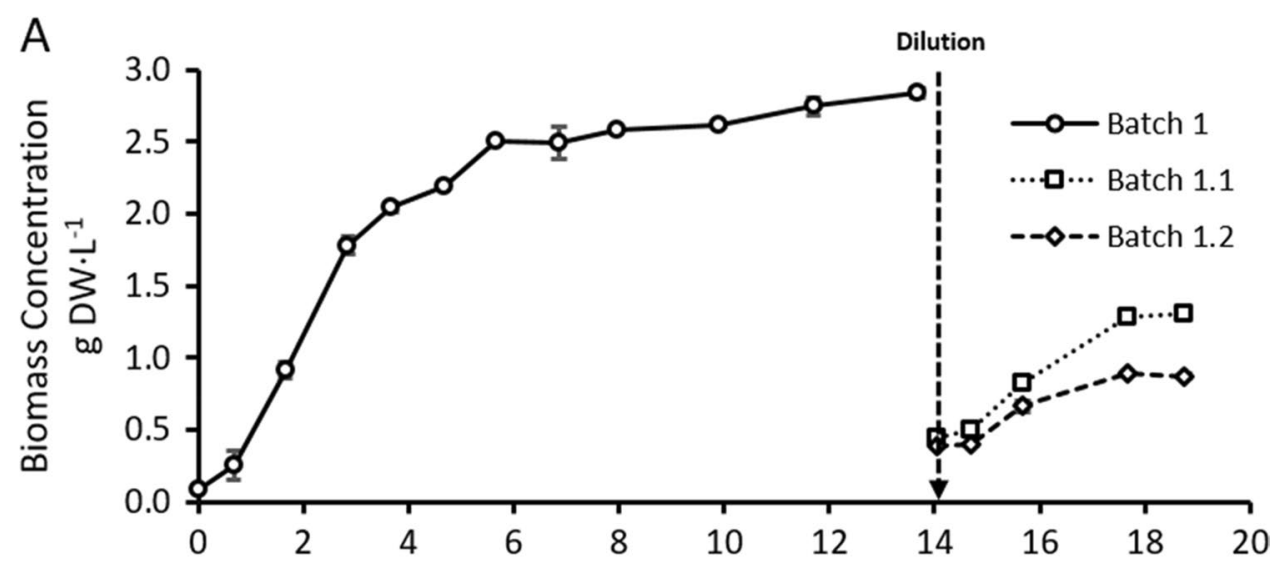

B

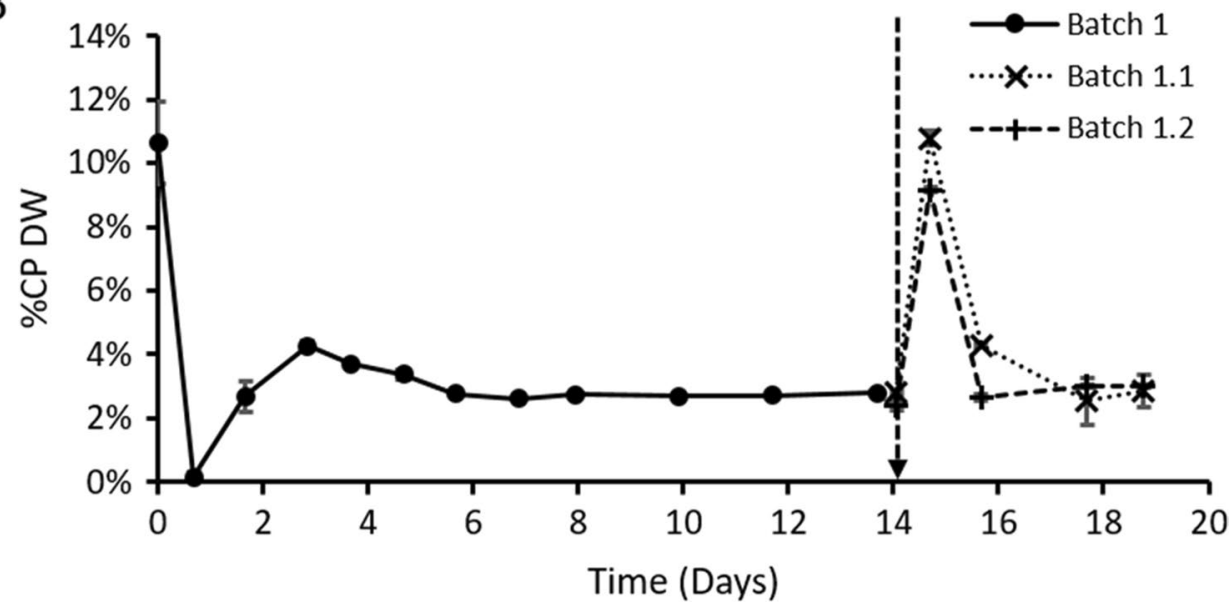


this purpose, on day 14 , the culture in batch 1 was divided and diluted into two PBRs: batch 1.1 and 1.2. The dilution was calculated such that after the dilution, the new cultures would have a phosphorus concentration of $1.5 \mathrm{mg} \mathrm{P} \mathrm{L}^{-1}$ in the medium together with additional $118 \mathrm{mg} \mathrm{N} \mathrm{L}^{-1}$. After the dilution, the cultures batch 1.1 and 1.2 started with a biomass concentration of $0.38 \mathrm{~g} \mathrm{DW} \mathrm{L}^{-1}$. The initial phosphorus uptake rate was very high, to such an extent that the phosphorus concentration in these samples was below the detection limit of the ICP-OES $\left(<0.1 \mathrm{mg} \mathrm{P} \mathrm{L}^{-1}\right)$.

On day 14, just after the dilution of batch 1 into two identical batch 1.1 and 1.2, the values of cyanophycin in the biomass were $2.8 \pm 0.1 \%$ and $2.4 \pm 0.2 \%$ respectively. On day 15 , within a day after the dilution, the cyanophycin content of the biomass rapidly increased to a transient accumulation of $10.8 \pm 0.2$ and $9.2 \pm 0.1 \%$ for batch 1.1 and 1.2 respectively (Fig. 4B). On day 16, the cyanophycin content decreased again to values of $4.3 \pm 0.1 \%$ and $2.7 \pm 0.1 \%$. After this decrease, cyanophycin content remained in values of $3.2 \pm 0.7 \%$ and $2.9 \pm 0.2 \%$ during days 16 to 18 .

Regarding cyanophycin productivity, the cyanophycin titers are more important than the biomass-specific cyanophycin content. The titers of cyanophycin were $75.1 \pm 0.1 \mathrm{mg} \mathrm{CP} \mathrm{L}^{-1}$ and $44.8 \pm 8.0 \mathrm{mg} \mathrm{CP} \mathrm{L}^{-1}$ in the peaks on day 3 (batch 1) and day 15 (average of batch 1.1 and 1.2) respectively. Thus, although the biomass cyanophycin content in batch 1.1 and 1.2 was higher than in batch 1, the cyanophycin titer in batch 1 was $79 \%$ higher. This is due to the difference in biomass concentration between days 3 and 15 of $1.76 \pm 0.06$ and $0.44 \pm 0.04 \mathrm{~g}$ DW L ${ }^{-1}$ respectively.

In batch 1, although phosphorus was already depleted on day 2 (Fig. 5), the biomass continued to grow linearly until day 5 (Fig. 4A), reaching a biomass concentration of $2.5 \mathrm{~g} \mathrm{DW} \mathrm{L}^{-1}$. A further increase in the biomass concentration after day 5 is not attributed to growth but to the gradual effect of water evaporation as the PBR was continuously aerated with a dry air- $\mathrm{CO}_{2}$ mixture (Fig. 4A). Both, the linear and stationary growth phases of batch 1 , were most likely the result of a combination of phosphorus and light limitation. The culture remained in stationary phase between days 5 and 14. (Fig. 4A).

At the time of the inoculation, $q_{\mathrm{P}}$ was determined by biomass analysis from a sample taken directly from the inoculum and its value was $4.63 \mathrm{mg} \mathrm{P} \mathrm{g}^{-1} \mathrm{DW}$. The $q_{\mathrm{P}}$ gradually decreased to a minimum of $1.84 \pm 0.04 \mathrm{mg} \mathrm{P} \mathrm{g}^{-1}$ DW and remained stable between days 5 and 14, period at which growth was no longer observed (Fig. 6). The values of $q_{\mathrm{P}}$ were determined by biomass digestion and direct measurement of the phosphorus content in the biomass by ICP.

After diluting batch 1 on day 14 , with a fresh media mix that added $1.5 \mathrm{mg} \mathrm{P} \mathrm{L}^{-1}$ extra, the $q_{\mathrm{P}}$ increased abruptly to 6.16 and $6.77 \mathrm{mg} \mathrm{P} \mathrm{g}^{-1} \mathrm{DW}$ in batch 1.1 and 1.2 , respectively (Fig. 6). This confirms the high phosphorus uptake rate of the biomass under phosphorus-starved conditions. Subsequently the $q_{\mathrm{P}}$ gradually decreased to values of 1.99 and $1.82 \mathrm{mg} \mathrm{P} \mathrm{g}^{-1} \mathrm{DW}$ on days 17 and 18 respectively, showing an asymptotic trend towards the minimum values observed in batch 1 .

\section{Discussion}

\section{Growth inhibition of Synechocystis 6803 by ammonium and urea}

High concentrations of ammonium nitrogen can inhibit growth of Synechocystis 6803. Concentrations of 0.50 $\mathrm{NH}_{4}{ }^{+}-\mathrm{N} \mathrm{L}^{-1}$ were found safe since this concentration resulted in only a $4 \%$ decrease in growth rate (Fig. 2). It is important to note that these results were obtained at a light intensity of $100 \mu \mathrm{mol}$ photons $\mathrm{m}^{-2} \mathrm{~s}^{-1}$, and in vertical tubes of $2.7-\mathrm{cm}$ diameter. Changes in both light intensity applied and light path are expected to have an effect on the level of inhibition observed in the culture as ammonium inhibition can be enhanced by light intensity (Drath et al. 2008). Continuous operation of PBRs for cultivation of
Fig. $5 \mathrm{NH}_{4}^{+}-\mathrm{N}$ concentration in medium during cultivation of Synechocystis 6803 under phosphorus-limiting conditions, at a $\mathrm{pH}$ of 7.5 , a temperature of $35^{\circ} \mathrm{C}$, and under a light intensity of $600 \mu \mathrm{mol}$ photons $\mathrm{m}^{-2} \mathrm{~s}^{-1}$. Error bars are the standard deviation of samples taken in duplicate and are covered by the marker if not visible

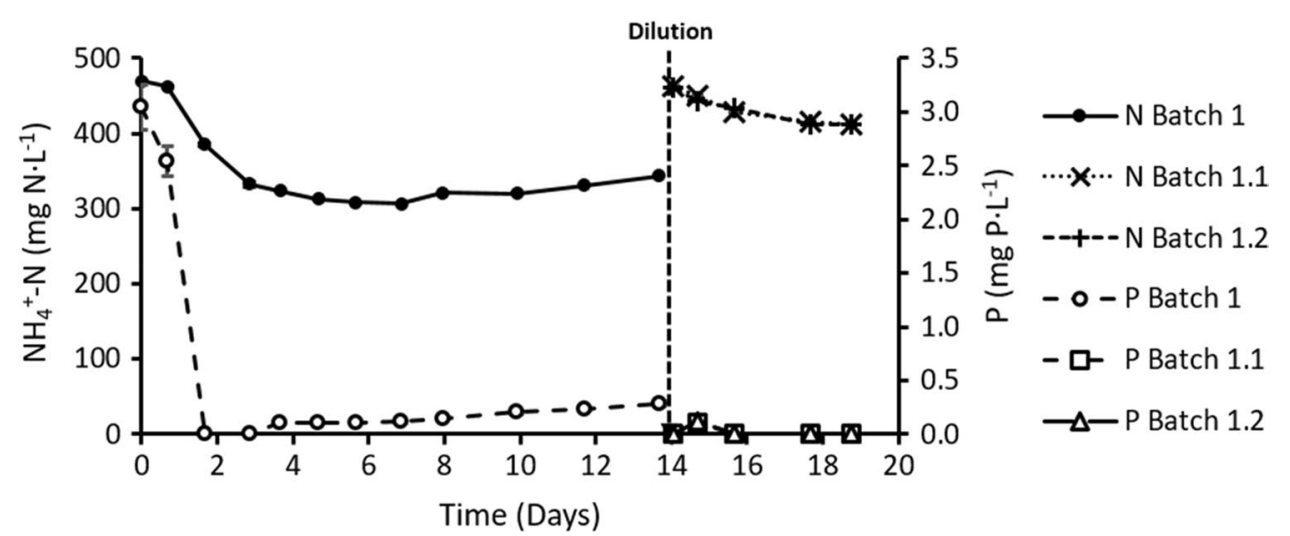


Fig. 6 Phosphorus quota $\left(q_{\mathrm{P}}\right)$ in Synechocystis 6803 biomass cultivated under phosphoruslimiting conditions, on ammonium as nitrogen source, at a $\mathrm{pH}$ of 7.5 , a temperature of $35^{\circ} \mathrm{C}$, and under a light intensity of $600 \mu \mathrm{mol}$ photons $\mathrm{m}^{-2} \mathrm{~s}^{-1}$. Error bars are the standard deviation of samples taken in duplicate and are covered by the marker if not visible

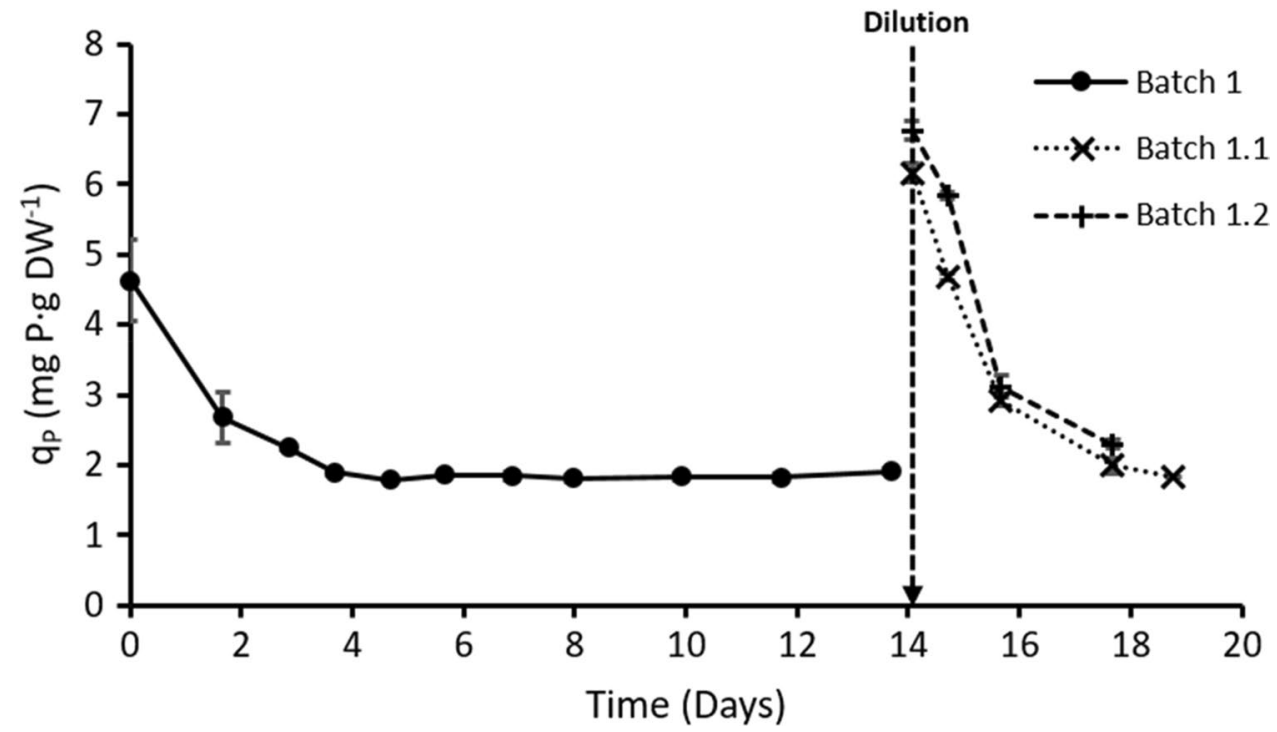

Synechocystis 6803 should aim for maximal nitrogen use/ recovery. Therefore, the hydraulic retention time should be determined in such a way that the ammonium nitrogen is efficiently used, resulting in very low concentrations of this compound in the medium.

Photosensitivity and photodamage during cultivation of cyanobacteria on ammonium is associated to the presence of free ammonia $\left(\mathrm{NH}_{3}\right)$. Since $\mathrm{NH}_{3}$ binds to the oxygen evolution centers as a competitive analogue to water (Evans et al. 2005), this results in an increased photosensitivity and photodamage of photosystem II (PSII) (Drath et al. 2008; Dai et al. 2014). It is important to note the $\mathrm{pH}$ dependency of the $\mathrm{NH}_{3} / \mathrm{NH}_{4}{ }^{+}$balance; at $\mathrm{pH}$ values above 9.25 (pKa of ammonium), the toxic form ammonia $\left(\mathrm{NH}_{3}\right)$ is the most abundant species. This makes $\mathrm{pH}$ an important parameter to control when considering cultivation of Synechocystis 6803 with ammonium as nitrogen source.

The fact that we observed inhibition already at a lower $\mathrm{NH}_{3}$ concentration at higher light intensity confirms that $\mathrm{NH}_{3}$ inhibition is enhanced at higher light intensity as suggested by Drath et al. (2008). In another study, Synechocystis 6803 showed photoinhibition at extracellular concentrations of $\mathrm{NH}_{3}$ above $70 \mathrm{mg} \mathrm{NH}_{3} \mathrm{~L}^{-1}$ under a light intensity of $10 \mu \mathrm{mol}$ photons $\mathrm{m}^{-2} \mathrm{~s}^{-1}$ (Drath et al. 2008). At a $\mathrm{pH}$ of 7.5 as applied in our experiments and a temperature of $35^{\circ} \mathrm{C}$, a concentration of $0.75 \mathrm{~g} \mathrm{NH}_{4}^{+}-\mathrm{N} \mathrm{L}^{-1}$ resulted in an $\mathrm{NH}_{3}$ concentration of $28.6 \mathrm{mg} \mathrm{NH}_{3} \mathrm{~L}^{-1}$, i.e., lower than the toxic value given by Drath et al. (2008).

Urea concentration did not seem to have an effect on the growth rate in actively growing cultures. The growth rates of Synechocystis 6803 did not deviate more than 5\% of the average for each light intensity. The drop in growth rate observed at a concentration of $0.45 \mathrm{~g}$ urea- $\mathrm{N} \mathrm{L}^{-1}$ of urea at both 100 and $200 \mu \mathrm{mol}$ photons $\mathrm{m}^{-2} \mathrm{~s}^{-1}$ cannot be explained. These values do not represent a typical inhibition pattern, with decreasing growth rates as concentrations increase. However, chlorosis occurred in growth-limited cultures cultivated in shaking flasks containing urea as sole nitrogen source (Fig. 3). This urea-triggered chlorosis was probably caused by an extreme case of free ammonia toxicity due to its accumulation in the cytosol. Sakamoto et al. (1998) suggest that urea-related chlorosis is caused due to the $\mathrm{pH}$ increase and the free ammonia formation and accumulation during intracellular ureolysis when growth is limited. Chlorosis occurs in stationary cultures of the urease-synthesizing cyanobacteria Synechocystis 6803, Synechococcus sp. PCC7002, and Anabaena sp. PCC7120, and does not occur in urease deletion mutants nor in the urease-negative strain Synechococcus sp. PCC6103 (Sakamoto et al. 1998). This suggests a connection of internal hydrolysis of urea with the urea-related chlorosis. Urea-triggered chlorosis is accentuated in growth-limited cultures possibly as a result of decreasing rates of nitrogen incorporation; as intracellular ureolysis can easily surpass the rate at which nitrogen is incorporated into metabolites (Mackerras and Smith 1986; Herrero et al. 2001).

Urea diffuses freely to the intracellular environment (Sachs et al. 2006; Esteves-Ferreira et al. 2018) and is rapidly hydrolyzed in an uncontrolled manner (Herrero et al. 2001). The presence of lipid peroxides in the urea-chlorotic cultures and the connection of urea chlorosis with the activity of urease (Sakamoto et al. 1998) suggest that ureatriggered chlorosis can be the result of a strong ammonia toxicity. Peroxidation of membrane lipids results from the presence of reactive oxygen species such as singlet oxygen generated as consequence of ammonia-enhanced photodamage (Dai et al. 2014). The ammonia toxicity caused by urea uptake is therefore stronger than the sole presence of free 
ammonia in stationary or growth-limited cultures resulting in a rapid and fatal chlorosis. We suggest that during active growth, less free ammonia can accumulate inside the cell as this is quickly metabolized; therefore, the toxicity of free ammonia is less strong and can be compensated by the photosystem repair mechanism. Urea-triggered chlorosis could be avoided by controlling the feeding of the PBR based on light availability (e.g., turbidostat/luminostat operation), dosing urea only when conditions allow active growth. Although in fresh urine most of the nitrogen is present in the form of urea, in stored urine, $>90 \%$ of the urea initially present is generally hydrolyzed in matter of hours (Kirchmann and Pettersson 1995). Therefore, in an operation with stored urine, the presence urea should not cause problems for the cultivation of Synechocystis 6803.

In synthesis, Synechocystis 6803 can grow at $\mathrm{NH}_{4}{ }^{+} \mathrm{N}$ concentrations up to $1.25 \mathrm{~g} \mathrm{NH}_{4}{ }^{+}-\mathrm{N} \mathrm{L}^{-1}$ (Fig. 2). However, we recommend not to expose Synechocystis 6803 to concentrations above $0.5 \mathrm{~g} \mathrm{NH}_{4}{ }^{+}-\mathrm{N} \mathrm{L}^{-1}$ to avoid growth inhibition during cultivation on hydrolyzed urine or similar streams. It is important to note that this only holds at $\mathrm{pH}$ below 7.5, a temperature below $35^{\circ} \mathrm{C}$, a light intensity of $100 \mu \mathrm{mol}$ photons $\mathrm{m}^{-2} \mathrm{~s}^{-1}$ and a light path through a tube of $2.7-\mathrm{cm}$ diameter. The presence of urea, as in fresh urine, needs to be carefully controlled, since the light intensity changes during the day/night cycles and light limitation can result in bleaching of the cultures due to chlorosis. Based on the typical ammonium nitrogen content of hydrolyzed urine, a dilution factor of 10 , and a pH of 7.5, the concentrations of ammonium typically present in stored urine are considered safe for the process. Moreover, in the case of a continuously operated PBR, it should be operated at nitrogen concentrations below $10 \mathrm{mg} \mathrm{N} \mathrm{L}^{-1}$ to warrant an effluent that complies with the requirements of the EU Water Framework Directive for the discharge to natural water bodies (Council Directive 91/271/ EEC 1991). Under these circumstances, nitrogen inhibition does not pose a problem for the process.

\section{Cyanophycin accumulation on ammonium due to phosphorus starvation}

The high cyanophycin content in the inoculum was not expected, but may be explained by a combination of phosphorus and light limitation during pre-cultivation at a light intensity of $200 \mu \mathrm{mol}$ photons $\mathrm{m}^{-2} \mathrm{~s}^{-1}$ and a medium with a concentration of $7 \mathrm{mg} \mathrm{P} \mathrm{L}^{-1}$ resulting in a $q_{\mathrm{P}}$ of $4.63 \mathrm{mg}$ $\mathrm{P} \mathrm{g}^{-1}$ DW as quantified by biomass analysis. As soon as the conditions allowed rapid growth after inoculation, the initial cyanophycin was rapidly consumed. Probably due to the phosphorus-limited conditions, cyanophycin accumulated again between days 1 and 3 (Fig. 4B). This peak in cyanophycin content coincided with the transition from linear to stationary growth, which is in line with observations by others (Allen et al. 1980; Gorelova and Kleimenov 2003). Subsequently, during stationary phase, the cyanophycin content slowly decreased and remained stable between days 7 and 14 at a value of $2.7 \%$, much higher than what is observed at the exponential phase $<1 \%$ (Simon 1973).

Accumulation of around 3\% CP and up to $18 \% \mathrm{CP}$ were reported by Watzer et al. (2015) when Synechocystis 6803 was cultivated under phosphorus starvation and axenic conditions using ammonium or nitrate, respectively, as nitrogen source. In this study, we reached a maximum transient cyanophycin content of $10.8 \pm 0.2 \%$ while cultivating on ammonium under non-axenic conditions, more than 3 times the $3 \%$ previously reported with ammonium as nitrogen source by Watzer et al. (2015) and significantly higher than the 7\% transient accumulation reported by Mackerras et al. (1990). Due to the rapid changes observed in the transient accumulation of cyanophycin, it remains to be seen if this can be exploited in a real system. The maximum content of cyanophycin in the biomass observed shortly after medium addition suggests a highly dynamic process of cyanophycin storage and consumption. Further insights in this process may be gained from sampling at higher temporal resolution.

Batch 1.1 and 1.2 had final biomass concentrations of 1.30 and $0.90 \mathrm{~g} \mathrm{DW} \mathrm{L}^{-1}$ on days 19 and 18 , respectively. It is difficult to explain why growth in the two PBRs started to diverge from each other (Fig. 4A). In batch 1.1 and 1.2, growth was limited mostly by a lack of phosphorus, since the fresh medium added contained plenty of other nutrients to support growth of the biomass to concentrations above $5 \mathrm{~g}$ DW L ${ }^{-1}$. Additionally, batch 1.1 and 1.2 reached biomass concentrations significantly lower than those in batch 1 , resulting in more light availability. In batch 1, we observed accumulation of cyanophycin due to phosphorus starvation combined with light limitation between days 1 and 3. In this case, growth slowed down while nitrogen was still available for uptake. In batch 1.1 and 1.2 however, we suggest the sudden accumulation of cyanophycin observed on day 15 is instead caused by the increase in ammonium concentration gradient between the intra- and extracellular environment that favored the uptake in combination with the alleviation of light limitation and a limited supply of phosphorus. Similar transient accumulation was observed in another strain of the same genus, Synechocystis sp. PCC6308, due to sudden addition of ammonium nitrogen to the medium (Mackerras et al. 1990). Accumulation of cyanophycin is generally attributed to adverse conditions such as depletion of a specific nutrient or light limitation, but it has also been attributed to sudden increases in nitrogen concentration (Mackerras et al. 1990; Watzer and Forchhammer 2018b). Moreover, the PII protein signaling system connects both ammonium uptake and cyanophycin production (Watzer et al. 2019). If ammonium uptake exceeds nitrogen organication, the (intracellular) excess of nitrogen can be accumulated as cyanophycin. 
Later on, when nitrogen organication exceeds ammonium uptake, cyanophycin would be degraded to serve as a nitrogen source (Watzer and Forchhammer 2018b).

Trautmann et al. (2016) studied the accumulation of cyanophycin under phosphorus starvation in Synechocystis 6803. The $q_{\mathrm{P}}$ values of $1-4 \mathrm{mg} \mathrm{P} \mathrm{g}^{-1} \mathrm{DW}$ were observed to trigger cyanophycin accumulation. They also found that growth of Synechocystis 6803 stopped when reaching a $q_{\mathrm{P}}$ of $1 \mathrm{mg} \mathrm{P} \mathrm{g}{ }^{-1} \mathrm{DW}$. These values presented by Trautmann et al. (2016) were determined by calculating the phosphorus uptake from a mass balance using the change of phosphate-P $\left(\mathrm{PO}_{4}{ }^{3-}-\mathrm{P}\right)$ in the medium and assuming the difference to be incorporated in the biomass. In our case, the actual $q_{\mathrm{P}}$ was determined by biomass digestion and direct measurement of the phosphorus content in the biomass by ICP, giving a minimum value of $1.84 \pm 0.04 \mathrm{mg} \mathrm{P} \mathrm{g}^{-1} \mathrm{DW}$ (Fig. 6).

Another important aspect is the high N:P ratio observed in the biomass. The $\mathrm{N}: \mathrm{P}$ ratio of the cultivation medium $276: 1$ is extremely high compared to the typical $\mathrm{N}: \mathrm{P}$ ratio of 16-22:1 in microalgae (Redfield 1958; Fernandes et al. 2017). In our experiments, the $\mathrm{N}: \mathrm{P}$ ratio of the biomass reached a maximum of $92: 1$ on day 5 , demonstrating the $\mathrm{N}: \mathrm{P}$ flexibility of Synechocystis 6803 biomass.

Despite phosphorus was depleted in the medium on day 2, Synechocystis 6803 biomass continued taking up nitrogen until reaching a removal of $33 \%$ of the nitrogen available in the medium on day 7 (Fig. 5). Nitrogen recovery continued for 5 days, even after phosphorus was depleted in the medium. This, combined with the high N:P ratio measured in the biomass and the cyanophycin content, suggests the possibility of achieving complete and simultaneous nitrogen and phosphorus uptake from $\mathrm{N}$-rich and P-poor streams such as urine or anaerobically treated black water (Fernandes et al. 2017). Cyanophycin production, however, still requires additional research to identify a suitable strategy to trigger accumulation to higher values more suitable for commercial opportunities, e.g., $40 \%$ in the case of PHA production from wastewater sludge (Werker et al. 2018).

\section{Conclusions}

Synechocystis 6803 was able to grow with ammonium and urea as nitrogen source, being able to assimilate the nitrogen sources present in source separated human urine. However, in order to avoid growth inhibition, the concentrations of ammonium nitrogen in the PBR should be kept at $0.5 \mathrm{~g} \mathrm{~N}$ $\mathrm{L}^{-1}$ or below. Urea inhibition was not observed during active growth at urea-nitrogen concentrations up to $0.7 \mathrm{~g} \mathrm{~N} \mathrm{~L}^{-1}$. However, in shaking flasks, stationary cultures cultivated on $0.5 \mathrm{~g} \mathrm{~N} \mathrm{~L}^{-1}$ urea uptake resulted in chlorosis. Therefore, presence of urea in the medium should be strategically controlled, e.g., by continuous cultivation maintaining good growth rates and low urea concentrations in turbidostat/ luminostat operation.

The cyanophycin content in the biomass of Synechocystis 6803 presented transient values up to $10.8 \pm 0.2 \% \mathrm{CP}$ while cultivated on ammonium. Synechocystis 6803 biomass reached extremely high $\mathrm{N}: \mathrm{P}$ ratios of up to $92: 1$, compared to what typical values for microalgae (16-22:1). This highlights the high potential of this process for simultaneous and complete recovery of nitrogen and phosphorus from nitrogen-rich and phosphorus-poor streams such as urine with the possibility of a combined production of cyanophycin.

Acknowledgements The authors would like to thank Pei-Hsuan Chen for his support with the treatment the digestion of some biomass samples and their analysis.

Funding This work was performed in the cooperation framework of Wetsus, European Centre of Excellence for Sustainable Water Technology (www.wetsus.nl). Wetsus is co-funded by the Dutch Ministry of Economic Affairs and Ministry of Infrastructure and Environment, the European Union Regional Development Fund, the Province of Fryslân and the Northern Netherlands Provinces.

Data availability Data is available upon request to corresponding author.

Open Access This article is licensed under a Creative Commons Attribution 4.0 International License, which permits use, sharing, adaptation, distribution and reproduction in any medium or format, as long as you give appropriate credit to the original author(s) and the source, provide a link to the Creative Commons licence, and indicate if changes were made. The images or other third party material in this article are included in the article's Creative Commons licence, unless indicated otherwise in a credit line to the material. If material is not included in the article's Creative Commons licence and your intended use is not permitted by statutory regulation or exceeds the permitted use, you will need to obtain permission directly from the copyright holder. To view a copy of this licence, visit http://creativecommons.org/licenses/by/4.0/.

\section{References}

Adamsson M (2000) Potential use of human urine by greenhouse culturing of microalgae (Scenedesmus acuminatus), zooplankton (Daphnia magna) and tomatoes (Lycopersicon). Ecol Eng $16: 243-254$

Al-Thawadi SM (2011) Ureolytic bacteria and calcium carbonate formation as a mechanism of strength enhancement of sand. J Adv Sci Eng Res 1:98-114

Allen MM, Hutchison F, Weathers PJ (1980) Cyanophycin granule polypeptide formation and degradation in the cyanobacterium Aphanocapsa 6308. J Bacteriol 141:687-693

Allen MM, Morris R, Zimmerman W (1984) Cyanophycin granule polypeptide protease in a unicellular cyanobacterium. Arch Microbiol 138:119-123

Allen MM, Weathers PJ (1980) Structure and composition of cyanophycin granules in the cyanobacterium Aphanocapsa 6308. J Bacteriol 141:959-962 
Cogne G, Gros JB, Dussap CG (2003) Identification of a metabolic network structure representative of Arthrospira (Spirulina) platensis metabolism. Biotechnol Bioeng 84:667-676

Connor R, Uhlenbrook S, Engin K, Renata Cordeiro Ortigara A (2017) The United Nations world water development report, 2017: wastewater: an untapped resource; executive summary. UNESCO Division of Water Science, Colombella, Italy, pp 1-12

Cornet JF, Dussap CG, Cluzel P, Dubertret G (1992) A structured model for simulation of cultures of the cyanobacterium Spirulina platensis in photobioreactors: II. Identification of kinetic parameters under light and mineral limitations. Biotechnol Bioeng 40:826-834

European Economic Community (1991) Council Directive 91/271/EEC of 21 May 1991 concerning urban waste-water treatment. Off J Eur Communities 135:40-52

Dai G-Z, Qiu B-S, Forchhammer K (2014) Ammonium tolerance in the cyanobacterium Synechocystis sp. strain PCC 6803 and the role of the psbA multigene family. Plant Cell Environ 37:840-851

Drath M, Kloft N, Batschauer A, Marin K, Novak J, Forchhammer K (2008) Ammonia triggers photodamage of photosystem II in the cyanobacterium Synechocystis sp. strain PCC 6803. Plant Physiol 147:206-215

Elbahloul Y, Krehenbrink M, Reichelt R, Steinbüchel A (2005) Physiological conditions conducive to high cyanophycin content in biomass of Acinetobacter calcoaceticus strain ADP1. Appl Environ Microbiol 71:858-866

Esteves-Ferreira AA, Inaba M, Fort A et al (2018) Nitrogen metabolism in cyanobacteria: metabolic and molecular control, growth consequences and biotechnological applications. Crit Rev Microbiol 44:541-560

Evans MCW, Ball RJ, Nugent JHA (2005) Ammonia displaces methanol bound to the water oxidizing complex of photosystem II in the S2 state. FEBS Lett 579:3081-3084

Feng D-L, Wu Z-C (2006) Culture of Spirulina platensis in human urine for biomass production and $\mathrm{O}_{2}$ evolution. J Zhejiang Univ Sci B 7:34-37

Fernandes TV, Suárez-Muñoz M, Trebuch LM et al (2017) Toward an ecologically optimized $\mathrm{N}$ : P recovery from wastewater by microalgae. Front Microbiol 8:1-6

Flores E, Herrero A (2005) Nitrogen assimilation and nitrogen control in cyanobacteria. Biochem Soc Trans 33:164-167

Fong RN, Kim K, Yoshihara C, Inwood WB, Kustu S (2007) The W148L substitution in the Escherichia coli ammonium channel AmtB increases flux and indicates that the substrate is an ion. Proc Nat Acad Sci 104:18706-18711

Forchhammer K, Schwarz R (2019) Nitrogen chlorosis in unicellular cyanobacteria - a developmental program for surviving nitrogen deprivation. Environ Microbiol 21:1173-1184

Goodman BE (2002) Transport of small molecules across cell membranes: water channels and urea transporters. Am J Physiol - Adv Physiol Educ 26:146-157

Gorelova OA, Kleimenov SY (2003) The accumulation and degradation dynamics of cyanophycin in cyanobacterial cells grown in symbiotic associations with plant tissues and cells. Microbiology 72:318-326

Hai T, Ahlers H, Gorenflo V, Steinbüchel A (2000) Axenic cultivation of anoxygenic phototrophic bacteria, cyanobacteria, and microalgae in a new closed tubular glass photobioreactor. Appl Microbiol Biotechnol 53:383-389

Herrero A, Muro-Pastor AM, Flores E (2001) Nitrogen control in cyanobacteria. J Bacteriol 183:411-425

Howarth RW (2008) Coastal nitrogen pollution: a review of sources and trends globally and regionally. Harmful Algae 8:14-20

Joentgen W, Groth T, Steinbüchel A, Hai T, Opperman FB (2001) Polyasparaginic acid homopolymers and copolymers, biotechnical production and use thereof. US patent 180752B1
Kampschreur MJ, Temmink H, Kleerebezem R, Jetten MSM, van Loosrecht MCM (2009) Nitrous oxide emission during wastewater treatment. Water Res 43:4093-4103

Kirchmann H, Pettersson S (1995) Human urine - chemical-composition and fertilizer use efficiency. Fertil Res 40:149-154

Kleiner D (1981) The transport of $\mathrm{NH}_{3}$ and $\mathrm{NH}_{4}{ }^{+}$across biological membranes. Biochim Biophys Acta 639:41-52

Kolodny NH, Bauer D, Bryce K, Klucevsek K, Lane A, Medeiros L, Mercer W, Moin S, Park D, Petersen J, Wright J, Yuen C, Wolfson AJ, Allen MM (2006) Effect of nitrogen source on cyanophycin synthesis in Synechocystis sp. strain PCC 6308. J Bacteriol 188:934-940

Krehenbrink M, Oppermann-Sanio FB, Steinbüchel A (2002) Evaluation of non-cyanobacterial genome sequences for occurrence of genes encoding proteins homologous to cyanophycin synthetase and cloning of an active cyanophycin synthetase from Acinetobacter sp. strain DSM 587. Arch Microbiol 177:371-380

Kromkamp J (1987) Formation and functional significance of storage products in cyanobacteria. N Z J Mar Freshw Res 21:457-465

Kujawa-Roeleveld K, Zeeman G (2006) Anaerobic treatment in decentralised and source-separation-based sanitation concepts. Rev Environ Sci Biotechnol 5:115-139

Lippi L, Bähr L, Wüstenberg A, Wilde A, Steuer R (2018) Exploring the potential of high-density cultivation of cyanobacteria for the production of cyanophycin. Algal Res 31:363-366

Liu Z, Zhao Q, Wang K, Lee D, Qiu W, Wang J (2008) Urea hydrolysis and recovery of nitrogen and phosphorous as MAP from stale human urine. J Environ Sci 20:1018-1024

Mackerras AH, de Chazal NM, Smith GD (1990) Transient accumulations of cyanophycin in Anabaena cylindrica and Synechocystis 6308. J Gen Microbiol 136:2057-2065

Mackerras AH, Smith GD (1986) Urease activity of the cyanobacterium Anabaena cylindrica. J Gen Microbiol 132:2749-2752

Maheswaran M, Ziegler K, Lockau W, Hagemann M, Forchhammer K (2006) PII -regulated arginine synthesis controls accumulation of cyanophycin in Synechocystis sp. train PCC 6803. J Bacteriol 188:2730-2734

Maurer M, Schwegler P, Larsen TA (2003) Nutrients in urine: energetic aspects of removal and recovery. Water Sci Technol 48:37-46

Messineo L (1966) Modification of the Sakaguchi reaction: spectrophotometric determination of arginine without previous hydrolysis. Arch Biochem Biophys 117:534-540

Montesinos ML, Muro-Pastor AM, Herrero A, Flores E (1998) Ammonium/methylammonium permeases of a cyanobacterium. J Biol Chem 273:31463-31470

Mooibroek H, Oosterhuis N, Giuseppin M, Toonen M, Franssen H, Scott E, Sanders J, Steinbüchel A (2007) Assessment of technological options and economical feasibility for cyanophycin biopolymer and high-value amino acid production. Appl Microbiol Biotechnol 77:257-267

Morales N, Boehler MA, Buettner S, Liebi C, Siegrist H (2013) Recovery of $\mathrm{N}$ and $\mathrm{P}$ from urine by struvite precipitation followed by combined stripping with digester sludge liquid at full scale. Water 5:1262-1278

Neumann K, Stephan DP, Ziegler K, Hühns M, Broer I, Lockau W, Pistorius EK (2005) Production of cyanophycin, a suitable source for the biodegradable polymer polyaspartate, in transgenic plants. Plant Biotechnol J 3:249-258

Nixon PJ, Barker M, Boehm M, de Vries R, Komenda J (2005) FtsHmediated repair of the photosystem II complex in response to light stress. J Exp Bot 56:357-363

Obst M, Steinbu A (2004) Microbial degradation of poly (amino acid) s. Biomacromol 5:1166-1176

Ortiz-ramirez C, Mora SI, Trejo J, Pantoja O (2011) PvAMT1;1, a highly selective ammonium transporter that functions as $\mathrm{H}^{+} / \mathrm{NH}_{4}^{+}$ symporter. J Biol Chem 286:31113-31122 
Redfield A (1958) The biological control of chemical factors in the environment. Am Sci 46:205-221

Rockström J, Steffen W, Noone K et al (2009) Planetary boundaries : exploring the safe operating space for humanity. Ecol Soc 14:32

Sachs G, Kraut JA, Wen Y et al (2006) Urea transport in bacteria: acid acclimation by gastric Helicobacter spp. J Membr Biol 212:71-82

Sakamoto T, Delgaizo VB, Bryant DA (1998) Growth on urea can trigger death and peroxidation of the cyanobacterium Synechococcus sp. strain PCC 7002. Appl Environ Microbiol 64:2361-2366

Siewe RM, Weil B, Burkovski A, Eggeling L, Krämer R, Jahns T (1998) Urea uptake and urease activity in Corynebacterium glutamicum. Arch Microbiol 169:411-416

Simon RD (1973) Measurement of the cyanophycin granule polypeptide contained in the blue green alga Anabaena cylindrica. J Bacteriol 114:1213-1216

Simon RD, Weathers P (1976) Determination of the structure of the novel polypeptide containing aspartic acid and arginine which is found in cyanobacteria. Biochim Biophya Acta - Protein Struct 420:165-176

Stanier RY, Kunisawa R, Mandel M, Cohen-Bazire G (1971) Purification and properties of unicellular blue-green algae (order Chroococcales). Bacteriol Rev 35:171-205

Sukenik A, Maldener I, Delhaye T (2015) Carbon assimilation and accumulation of cyanophycin during the development of dormant cells (akinetes) in the cyanobacterium Aphanizomenon ovalisporum. Front Microbiol 6:01067

Trautmann A, Watzer B, Wilde A et al (2016) Effect of phosphate availability on cyanophycin accumulation in Synechocystis sp. PCC 6803 and the production strain BW86. Algal Res 20:189-196

Tuantet K, Janssen M, Temmink H, Zeeman G, Wijffels RH, Buisman CJN (2014a) Microalgae growth on concentrated human urine. J Appl Phycol 26:287-297

Tuantet K, Temmink H, Zeeman G, Janssen M, Wijffels RH, Buisman CJN (2014b) Nutrient removal and microalgal biomass production on urine in a short light-path photobioreactor. Water Res $55: 162-174$

Valladares A, Montesinos ML, Herrero A, Flores E (2002) An ABCtype, high-affinity urea permease identified in cyanobacteria. Mol Microbiol 43:703-715 van Alphen P, Abedini Najafabadi H, Branco dos Santos F, Hellingwerf KJ (2018) Increasing the photoautotrophic growth rate of Synechocystis sp. PCC 6803 by identifying the limitations of its cultivation. Biotechnol J 1700764:1-8

Vasconcelos Fernandes T, Shrestha R, Sui Y, Papini G, Zeeman G, Vet LEM, Wijffels RH, Lamers P (2015) Closing domestic nutrient cycles using microalgae. Environ Sci Technol 49:12450-12456

Watzer B, Engelbrecht A, Hauf W, Stahl M, Maldener I, Forchhammer K (2015) Metabolic pathway engineering using the central signal processor PII. Microb Cell Fact 14:192

Watzer B, Forchhammer K (2018) Cyanophycin: a nitrogen-rich reserve polymer. In: Tiwari A (ed) Cyanobacteria. IntechOpen, Riejeka, pp 85-107

Watzer B, Forchhammer K (2018b) Cyanophycin synthesis optimizes nitrogen utilization in the unicellular cyanobacterium Synechocystis sp. Strain PCC 6803. Appl Environ Microbiol 84:e01298-e1318

Watzer B, Spät P, Neumann N, Koch M, Sobotka R, Macek B, Hennrich O, Frchhammer K (2019) The signal transduction protein PII controls ammonium, nitrate and urea uptake in cyanobacteria. Front Microbiol 10:1428

Werker A, Bengtsson S, Korving L et al (2018) Consistent production of high quality PHA using activated sludge harvested from full scale municipal wastewater treatment - PHARIO. Water Sci Technol 78:2256-2269

Zavrel T, Sinetova MA, Búzová D, Literákova P, Červený, (2015) Characterization of a model cyanobacterium Synechocystis sp: PCC 6803 autotrophic growth in a flat-panel photobioreactor. Eng Life Sci 15:122-132

Zhang S, Lim CY, Chen CL, Liu H, Wang JY (2014) Urban nutrient recovery from fresh human urine through cultivation of Chlorella sorokiniana. J Environ Manage 145:129-136

Publisher's note Springer Nature remains neutral with regard to jurisdictional claims in published maps and institutional affiliations. 